\title{
Grenzeloze Zorg!
}

Citation for published version (APA):

van Gemert, W. (2018). Grenzeloze Zorg! Maastricht University. https://doi.org/10.26481/spe.20181220wg

Document status and date:

Published: 20/12/2018

DOI:

$10.26481 / \mathrm{spe} .20181220 \mathrm{wg}$

Document Version:

Publisher's PDF, also known as Version of record

\section{Please check the document version of this publication:}

- A submitted manuscript is the version of the article upon submission and before peer-review. There can be important differences between the submitted version and the official published version of record.

People interested in the research are advised to contact the author for the final version of the publication, or visit the DOI to the publisher's website.

- The final author version and the galley proof are versions of the publication after peer review.

- The final published version features the final layout of the paper including the volume, issue and page numbers.

Link to publication

\footnotetext{
General rights rights.

- You may freely distribute the URL identifying the publication in the public portal. please follow below link for the End User Agreement:

www.umlib.nl/taverne-license

Take down policy

If you believe that this document breaches copyright please contact us at:

repository@maastrichtuniversity.nl

providing details and we will investigate your claim
}

Copyright and moral rights for the publications made accessible in the public portal are retained by the authors and/or other copyright owners and it is a condition of accessing publications that users recognise and abide by the legal requirements associated with these

- Users may download and print one copy of any publication from the public portal for the purpose of private study or research.

- You may not further distribute the material or use it for any profit-making activity or commercial gain

If the publication is distributed under the terms of Article $25 \mathrm{fa}$ of the Dutch Copyright Act, indicated by the "Taverne" license above, 
Prof.Dr. Wim G. van Gemert

Faculty of Health, Medicine and Life Sciences

\section{Grenzeloze Zorg!}


Geachte prorector, geachte aanwezigen,

Grenzeloze zorg! De titel van mijn rede. Het is de korte versie van de titel die ik initieel in gedachten had: "Grenzen aan Zorg of Zorg zonder Grenzen". Als gevolg van deze grenzen wordt het ons moeilijk gemaakt om goede chirurgische zorg voor het kind te leveren in een regio die dit juist hard nodig heeft. Deze grenzen kunnen uitgelegd worden als fysieke landsgrenzen, grenzen aan het vakgebied kinderchirurgie, maar ook grenzen opgelegd door beroepsverenigingen, nationale en Europese politieke organen.

In mijn rede leg ik $u$ uit dat grensoverschrijdende samenwerking tussen de kinderchirurgische centra in de Euregio Maas-Rijn, de beste oplossing is om een hoogwaardige kinderchirurgische zorg in deze regio te behouden en verder te ontwikkelen.

$\mathrm{Na}$ een korte uiteenzetting van mijn professionele gang naar de huidige positie, geef ik mijn visie omtrent de recentelijke ontwikkelingen binnen ons vakgebied en zal ik onze visie en strategie aan u voorleggen en onderbouwen.

In 1998 begon ik aan mijn opleiding tot kinderchirurg in Amsterdam. Mijn eerste opleider was prof. Anton Vos en later prof. Hugo Heij. Daar werd ik breed opgeleid omdat alle deelgebieden van ons vak goed 
vertegenwoordigd waren: aangeboren aandoeningen, oncologische chirurgie, colorectale chirurgie, endocriene chirurgie, thoraxchirurgie, traumatologie, urologie, enzovoorts.

Op 31 december van het jaar 2000 om middernacht precies was mijn opleiding tot kinderchirurg officieel volbracht en kreeg ik de dubieuze eer om tijdens de millenniumwisseling in het ziekenhuis, wegens de dreiging van de millenniumbug, dienst te mogen doen als volwaardig kinderchirurg.

In die periode heb ik ook mijn promotieonderzoek afgerond en mijn doctorstitel verkregen. Mijn promotieonderzoek is verricht onder supervisie van prof. Peter Soeters en prof. Jan Willem Greve en was getiteld: "De chirurgische behandeling van morbide obesitas: technische, psychosociale, en metabole aspecten".

Daarna ben ik nog enkele jaren in de staf kinderchirurgie in Amsterdam werkzaam geweest.

Vervolgens ben ik om verschillende redenen eind 2002 teruggekomen naar Maastricht waar ik mij vooral heb beziggehouden met de gastro-intestinale en colorectale chirurgie in al zijn facetten. De kinderchirurgie deed ik in die tijd mondjesmaat. Van 2009 tot 2014 heb ik op verschillende plaatsen in nietacademische ziekenhuizen gewerkt. 
In 2014 werd ik door prof. Ernst van Heurn, destijds hoofd van de kinderchirurgie in Maastricht, gevraagd om weer voor de kinderchirurgie te komen werken. $\mathrm{Na}$ alle omzwervingen voelde ik mij goed om mijn plaats. Voor mij bleek de kinderchirurgie wederom het mooiste vakgebied om verschillende redenen. Bijna iedereen heeft een natuurlijke affiniteit met kinderen en een sterke drang tot protectie. Het lijkt onrechtvaardig dat zo'n weerloos en onschuldig wezen ziek wordt. Hen helpen gaat als vanzelf, heel natuurlijk. De behandeling van jonge mensen, kinderen en ouders, kent het grootste rendement wat betreft kwaliteit van leven en geeft daarom veel voldoening. In principe wordt de kinderchirurgie slechts beperkt door de leeftijd en niet door orgaansystemen of specifieke ziektebeelden.

Aangezien de meeste specialismen, orgaan-specifiek zijn, ontstaat hier evenwel competitie. Bijvoorbeeld de leverchirurg is vaak van mening dat feitelijk alle leverchirurgie bij hen hoort; de aangeboren aandoeningen, de goedaardige en de kwaadaardige aandoeningen, ongeacht de leeftijd.

Alhoewel de kinderchirurgie nog steeds een van de meest holistische chirurgische vakgebieden is, zijn bepaalde specifieke delen van de kinderchirurgie geheel of gedeeltelijk overgenomen door andere vakgebieden, zoals de kinderurologie, kinderlongchirurgie, kindertraumatologie en kinder- 
transplantatiechirurgie. Dit fenomeen speelt mee op de achtergrond van vele recentelijke ontwikkelingen en beslissingen.

In april 2015 kwam ik definitief terug naar Maastricht om mijn huidige positie te vervullen. Ik kwam terecht in een bijzondere en zeer uitdagende situatie. Van de staf was alleen Marc Dirix nog aanwezig die halftijds in Maastricht standhield naast zijn praktijk in Luik: "de rots in de branding". Voor de diensten werd prof. Gerd Steinau, kinderchirurg uit Aken, bereid gevonden om te helpen. De researchactiviteiten waren ook grotendeels verdwenen.

Daarbij kwam dat er vanuit de beroepsverenigingen een grote druk werd uitgeoefend om specialistische zorg verder te centreren in twee centra. Er werd een rapport gepubliceerd, "Concentratie Kinderchirurgie", door Schellekens en Van der Wal in opdracht van de beroepsvereniging, waarbij de noodzaak tot centralisatie van de kinderchirurgische zorg werd benadrukt.

Alhoewel hiernaar wordt gerefereerd als onderzoek, is daar geen enkele sprake van. Dit "onderzoek" maakt zich schuldig aan elke denkbare onderzoeksbias en confounder, waardoor dit rapport weinig betekenis heeft en niets meer is dan een mening. Een voorbeeld is het confirmatiebias waarbij een data-analyse wordt 
uitgevoerd om een van tevoren bedachte assumptie te bewijzen.

Desalniettemin werd dit rapport geaccepteerd als uitgangssituatie waarmee de kinderchirurgie zich aansluit bij de landelijke ontwikkelingen in de volwassen chirurgie. In dit rapport werd simpelweg gesteld dat Maastricht genoodzaakt was te stoppen met de behandeling van de indexdiagnosen. Dit werd door de oud-inspecteur schaamteloos en levensgroot gepresenteerd op de chirurgendagen, het landelijke congres voor alle chirurgen in Nederland.

De indexdiagnosen zijn de aangeboren aandoeningen, zoals de oesophagusatresie, anorectale malformaties, ziekte van Hirschsprung, galgangatresie, longafwijkingen, gastroschizis en omphalocêle. De kinderoncologische zorg was reeds gecentreerd in het Prinses Maxima Centrum te Utrecht. Hiermee zou het grootste deel van de typische kinderchirurgie uit Maastricht verdwijnen en slechts de algemene chirurgische zorg voor het kind overblijven. Het verdwijnen van de kinderchirurgie zou een aanzienlijke nevenschade veroorzaken, zoals de negatieve gevolgen voor de praktijken en soms opleidingsbevoegdheden van een aantal aanpalende specialismen, te denken aan de kindergeneeskunde, neonatologie, neonatale en kinder-intensive care, gynaecologie en obstetrie, kinderurologie, kinderradiologie en kinderanesthesiologie. Daarenboven, 
heeft het ziekenhuis de verplichting om goede regionale zorg voor het kind te waarborgen.

$\mathrm{Er}$ is aldus veel aan gelegen om de kinderchirurgie in Maastricht te behouden. Alleen al de zeer excentrische ligging van Maastricht in Nederland zou voldoende reden moeten zijn om de kinderchirurgie grotendeels in Maastricht te behouden, om een goede spreiding van de chirurgische zorg voor het kind en daarmee ook de algemene zorg voor het kind te waarborgen.

Overigens heeft het rapport "Concentratie Kinderchirurgie", en later het normdocument, ook positieve gevolgen gehad. Op basis van dit rapport zijn de kinderchirurgische centra actief aan de slag gegaan om aan kwaliteitsnormen te voldoen: het completeren van de kinderchirurgische staf, opzetten van zorgpaden, intensiveren van contacten met de patiëntenverenigingen, en zo verder. Men is creatief gaan nadenken over de organisatie van de kinderchirurgische zorg in Nederland. Daarnaast is er een constructief en vruchtbaar landelijk overleg ontstaan waarbij alle kinderchirurgische centra in Nederland betrokken zijn.

Het rapport "Concentratie Kinderchirurgie" werd gevolgd door het normdocument, waarin de normen zijn vastgelegd waaraan een kinderchirurgisch centrum moet voldoen. De belangrijkste norm die gesteld werd, 
in navolging van de volwassen chirurgie, zijn de minimale aantallen procedures. Een minimaal vereist aantal procedures per indexdiagnose per jaar en per locatie is noodzakelijk om toestemming te krijgen betreffende aandoeningen te blijven behandelen. Maar waar zijn deze normaantallen op gebaseerd? Is er een bewijs voor de hoogte van deze norm? Het antwoord is "nee". Uiteraard is het voor iedereen duidelijk dat ervaring telt: "als u een behandeling 100 maal per jaar uitvoert in verhouding tot 2 maal per jaar, dan zult $\mathrm{u}$ in het eerste geval betere resultaten behalen. Maar is dat ook waar in geval van 11 behandelingen in verhouding tot 7 ? Hetgeen een meer realistische verhouding is in geval van de kinderchirurgie. En praten we hier over ervaring met de operatieve techniek of ervaring met de totale behandeling, het team, of het zorgpad? Nauwelijks worden andere parameters zoals patiënttevredenheid, behandelresultaten of complicaties in de discussie betrokken, die toch voortvloeien uit de kwaliteit van de zorg.

Er zijn niet meer calamiteiten in de centra die een bepaalde aangeboren aandoening minder behandelen. Vorig jaar werd op de wetenschappelijke vergadering van de BELAPS, de Belgische beroepsvereniging voor kinderchirurgie, de lange termijn resultaten gepresenteerd van 120 patiënten met een oesophagusatresie, oftewel een aangeboren 
slokdarmafsluiting, behandeld in maar liefst 18 kinderchirurgische centra. Hetgeen betekent een gemiddelde van 1.2 slokdarmafsluitingen per centrum per jaar. De resultaten waren precies hetzelfde als de resultaten gerapporteerd door de grotere centra in de wereld; hetzelfde functionele resultaat en dezelfde complicatierisico's.

Nog dit jaar werd op het jaarcongres van de EUPSA, het belangrijkste Europese congres op het gebied van de kinderchirurgie, een systematische review gepresenteerd over de resultaten van operaties bij kinderen door een kinderchirurg vergeleken met de volwassen chirurg. Het ging om aandoeningen zoals invaginatie, malrotatie en volvulus, blindedarmontsteking, kinder-liesbreuk, kinderpolytrauma, pylorushypertrofie, algemene en neonatale chirurgie. Hierbij moet men bedenken dat in veel landen de kinderchirurgie ook vaak door de volwassen chirurg wordt uitgevoerd en er geen sprake is van concentratie van de kinderchirurgie. Ondanks het significant lagere volume door de kinderchirurg geopereerd, bleek de uitkomst in alle gevallen beter: significant minder complicaties, minder darmresecties, minder perforaties en kortere opnameduur. In geval van ernstige kindertrauma's opgevangen en behandeld in een kinder-traumacentrum zelfs een significant betere overleving. 
In de volwassen chirurgie worden voor verschillende procedures totaal verschillende normaantallen gehanteerd. Deze aantallen zijn niet gebaseerd op de complexiteit van de procedure noch is bewezen dat "kwantiteit" de belangrijkste determinant van kwaliteit is.

Vervolgens moet dit aantal per locatie worden verricht. Vooral in de grensregio is dat een probleem. Als men bedenkt dat de procedures worden verricht door hetzelfde team, dezelfde operatieprotocollen en materialen en dezelfde zorgpaden, in nabijgelegen locaties van één grensoverschrijdend kinderchirurgisch centrum; is het dan niet redelijk om de procedures als één centrum te registreren?

Wij hebben aldus geen onderbouwd idee van wat het absolute aantal moet zijn. Naar mijn mening is deze grens louter politiek bepaald! In navolging van de volwassen chirurgie, loert ook bij de kinderchirurgie het gevaar dat de normaantallen langzaam worden opgevoerd om uiteindelijk tot twee kinderchirurgische centra in Nederland te komen. Naar mijn mening, is dat een onwenselijke en onhaalbare situatie met negatieve gevolgen voor de zorg van het kind in Nederland.

Dit gezegd hebbende, is het helder dat een vorm van concentratie van zorg voor zeldzame aandoeningen noodzakelijk is en de normaantallen hiervoor zijn 
vastgesteld. Voor onze situatie in de grensregio is aldus een veel belangrijkere vraag: "Mag ons grensoverschrijdende kinderchirurgische instituut als één centrum registreren, zodat de normaantallen ruimschoots gehaald kunnen worden?".

Naar mijn mening, is het gepast om voor de grensregio een uitzonderingssituatie te maken. Mocht dit uiteindelijk niet het geval zijn, dan voelen wij ons genoodzaakt om de behandeling van een aantal zeldzame aandoeningen binnen ons Euregionaal netwerk te centreren.

Wanneer de situatie nader bekeken wordt, blijken er meer dan voldoende mogelijkheden om de kinderchirurgie te behouden en zelfs voldoende regionale potentie om een kinderchirurgisch centrum van formaat te worden.

De geografische ligging van Maastricht in het uiterste zuiden van het land voor $97 \%$ omgeven door grenzen is een groot nadeel, maar is tegelijk veelbelovend. Zo excentrisch als Maastricht in Nederland ligt, zo centraal ligt Maastricht in de Euregio Maas-Rijn. Daarnaast werd bijna gelijktijdig met mijn aanstelling, prof. Ulf Neumann benoemd tot voorzitter van de gehele vakgroep chirurgie in Maastricht UMC+ en de Uniklinik Aken. De relatie met Centre Hospitalier Chrétien in Luik was ook reeds aanwezig via Marc Dirix. 
Hiermee was bereids een goede basis voor de grensoverschrijdende kinderchirurgie gelegd.

De meeste grensregio's kennen slechts twee aangrenzende landen, terwijl de euregio Maas-Rijn drie aangrenzende landen betreft, namelijk Nederland, Duitsland en België. En kent drie kinderchirurgische centra die erg dicht bij elkaar gelegen zijn in Maastricht, Aken en Luik met een onderlinge afstand van ongeveer $20 \mathrm{~km}$. Daarnaast hebben alle drie de centra dezelfde grensperikelen en zijn zich hiervan bewust, waardoor er een grote bereidwilligheid is om samen te werken.

In alle drie de centra wordt geïnvesteerd in het moeder-kind centrum, hetgeen zich onder meer uit in de bouw van nieuwe en moderne OK-complexen, neonatale intensieve zorg, kinderafdelingen en poliklinieken op alle locaties. De fusie van Centre Hospitalier Chrétien in Luik wordt de nieuwe Clinique du Montlegia; een prachtig 1000-bedden ziekenhuis met een belangrijk focus op moeder-kind.

Zonder deze samenwerking wordt het voortbestaan van alle drie de kinderchirurgische centra bedreigd, echter, een effectieve samenwerking van deze drie heeft een enorme potentie door de bundeling van expertise, ervaring en klinische praktijk.

Op alle fronten lijkt er juist nu een momentum te zijn ontstaan om de grensoverschrijdende collaboratie voor de kinderchirurgie te realiseren. 
De samenwerking binnen de Euregio Maas-Rijn is wat ons betreft de beste en misschien wel enige optie om de kinderchirurgie te behouden en verder te ontwikkelen.

Wat is nu eigenlijk de Euregio Maas-Rijn?

De Euregio Maas-Rijn bestaat uit de regio Aken, Zuidlimburg, Belgisch Limburg, Luik, en Oost-Belgie. In Nederland tellen we Midden-Limburg en deels NoordLimburg en Brabant ook tot onze regio. Dit betreft een populatie van bijna 6 miljoen inwoners en ongeveer 50.000 levendgeborenen per jaar. Kortom, als op termijn deze regio volledig draineert op het Euregionale kinderchirurgisch centrum, is er geen discussie meer omtrent de aantallen.

Eutropolis geeft een andere interessante kijk op de Euregio door de plattegrond van de Londense metro over de Euregio te projecteren: "een nieuw soort stad". Men ziet dan een internationaal, deels stedelijk, deels groengebied, met 4 miljoen inwoners, drie nationaliteiten, drie talen en vele opleidingen en culturele instellingen.

In de notitie "Op zoek naar de Euregio-factor" worden duidelijke data gegeven omtrent de Euregio Maas-Rijn. Het blijkt dat er sprake is van een significant zwakkere socio-economische status, een significant slechtere gezondheidstoestand en kortere levensverwachting. 
Juist in dit gebied is het behoud van een goede chirurgisch zorg voor het kind, en daarmee ook de algemene zorg voor het kind, van essentieel belang. Het mag niet zo zijn, dat een kind met een aangeboren aandoening of complexe aandoening, die zo onfortuinlijk is om in deze regio geboren te worden, minder toegang heeft tot goede zorg. Dat is niet acceptabel in een beschaafd land.

Een goede spreiding van specifieke zorg is de verantwoordelijkheid van de dokters en de ziekenhuizen, maar ook van de beroepsverenigingen, zorgverzekeraars, patiëntenverenigingen en de politiek.

Nogal eens zijn de dichtstbijzijnde kinderchirurgische centra 2 tot 5 uur reizen verwijderd. Daarbij komt dat de meeste aangeboren aandoeningen een chronische behandeling behoeven. Als de ervaring met de chirurgische behandeling van specifieke aandoeningen verdwijnt zal de expertise en uiteindelijk ook het zorgpad verdwijnen, waardoor ook het vervolg elders moet plaatsvinden.

Dit houdt in dat het kind en de ouders in deze gevallen ver en veelvuldig moeten reizen en verblijven om bij hun zieke kind te kunnen zijn. Behalve de kosten hiervan, die niet onaanzienlijk zijn, en die juist in onze regio een significant probleem vormen, zijn er meer gevolgen zoals voor het werk van de ouders en de 
emotionele belasting. Het is te gemakkelijk gezegd:

"Dat moet u maar voor uw kind over hebben".

Zeker indien we in ogenschouw nemen dat bijna alle faciliteiten en kinderspecialisten in onze Euregio vertegenwoordigd zijn met een grote bedden- en OKcapaciteit en korte reisafstanden.

Welnu, de oplossing is duidelijk: Grensoverschrijdende samenwerking te beginnen bij de Euregio Maas-Rijn. Maar dat is nog niet zo eenvoudig als het klinkt. En hoewel de Europese Unie samenwerking over de grens nastreeft, is er een complexe wet- en regelgeving gemaakt die dit bemoeilijkt. Zeker wanneer het de gezondheidszorg betreft. Om u een idee te geven, zal ik enkele voorbeelden noemen:

- De formatie van een internationaal erkend kinderchirurgisch team;

- Professionele kwalificaties;

- Erkenning als één grensoverschrijdend kinderchirurgisch instituut;

- Het juridisch construct;

- Verschillende financieringsstructuren;

- Dataregistratie en extractie;

- Europese privacy-wetgeving;

Centraal staat een goed en efficiënt team van kinderchirurgen die niet alleen het gewenste chirurgische profiel hebben, maar ook wat betreft de 
persoonlijkheidsstructuur bij elkaar passen. Mede gezien het feit dat er geen opgeleide kinderchirurgen voorhanden zijn, hebben wij besloten om geschikte chirurgen verder op te leiden tot kinderchirurg. Het opleiden van chirurgen tot kinderchirurg heeft, ten opzichte van het opleiden van een differentiant kinderchirurgie gedurende de algemene opleiding chirurgie, meerdere voordelen. Zij hebben meer ervaring, waardoor hun chirurgische vaardigheden en hun geschiktheid voor het team veel beter te beoordelen zijn. Daarnaast zijn zij om dezelfde reden beter en sneller op te leiden.

Een belangrijk wapenfeit is de erkenning van de volledige opleiding kinderchirurgie als opleidingsinstituut Aken-Maastricht door de Ärztekammer in Duitsland.

Verder maken wij gebruik van kinderchirurgen die nog een andere specialisatie hebben in de volwassen chirurgie in lijn met hun focus binnen de kinderchirurgie: dit noemen wij "hybride kinderchirurgen".

Bijvoorbeeld: een kinderchirurg met een focus op anorectale malformaties die daarnaast een gecertificeerd colorectaal chirurg is of een kinderchirurg met een focus op de leveraandoeningen die tevens een gecertificeerd leverchirurg is. Deze constructie geeft vele voordelen. Het belangrijkste 
voordeel is een forse toename in ervaring en expertise in de behandeling van een bepaald orgaansysteem. De hybride kinderchirurg behandelt min of meer hetzelfde aantal specifieke indexdiagnosen, maar de rest van de werktijd wordt gevuld met operaties aan hetzelfde orgaansysteem, echter bij grotere kinderen, adolescenten en volwassenen. Hij of zij vergroot daarmee de kennis en kunde van de behandeling van aandoeningen van het betreffende orgaansysteem. Een ander voordeel is het feit dat de hybride kinderchirurg de patiënt gedurende het gehele leven kan blijven begeleiden, waarmee ook de transitie naar de volwassenheid vloeiend kan verlopen. Vervolgens is de hybride chirurg beter inzetbaar voor het ziekenhuis. Volgens de norm moeten er minstens 6 en bij voorkeur 8 kinderchirurgen in een centrum aangesteld zijn om continuïteit te waarborgen en een acceptabel dienstrooster te kunnen hanteren. Het merendeel van de centra hebben onvoldoende activiteit om dit aantal kinderchirurgen fulltime in de kinderchirurgie te laten werken. De hybride kinderchirurgen kunnen de kinderchirurgie beoefenen en deels werkzaam zijn binnen hun focus bij de volwassen chirurgie. Dit genereert een betere en efficiëntere inzet van specialisten, terwijl toch het vereiste aantal kinderchirurgen werkzaam zijn.

Bij een aantal vakbroeders heerst de zorg dat deze opzet een bedreiging voor de kinderchirurgie kan 
vormen. In mijn visie is juist het omgekeerde meer waarschijnlijk. Door specialisten op te leiden met een duale expertise binnen de kinderchirurgie, is de kans op het behoud van specifieke vakgebieden binnen de kinderchirurgie juist groter geworden.

Inmiddels is ons chirurgisch team bijna compleet. Momenteel bestaat het totale team uit 10 kinderchirurgen waarvan 3 nog in opleiding. Dit is één team werkzaam op 3 locaties en gefinancierd door 3 locaties.

Verder zijn er een drietal volwassen chirurgen betrokken die ook de grotere kinderen behandelen met een speciaal focus op de thoraxchirurgie, leverchirurgie en colorectale chirurgie.

Dit team wordt ondersteund door een physician assistent, Dianne Dinjens en een manager assistent, Miriam Habex, hetgeen de effectiviteit van het chirurgisch team enorm ten goede komt. Als gevolg van de grote compatibiliteit tussen de zittende kinderchirurgen in Maastricht, Aken en Luik, en door een effectieve selectie en opleiding, hebben we een uitstekend kinderchirurgisch team.

Ik durf te stellen dat we ons thans kunnen meten met de beste teams in de Benelux.

Van belang is dat de kinderchirurgie gesitueerd is binnen de algemene chirurgie. Gezien het holistische karakter van de kinderchirurgie is dit de meest logische 
en efficiënte positie. Het bevordert de samenwerking met de volwassen specialisten in de verschillende facetten van ons vak, vooral de zeldzamere en meer complexe pathologie. Gezien het feit dat bijna alle klinische innovaties in de volwassen chirurgie ontstaan en de kinderchirurgie daar steevast achteraanloopt, kan ook de introductie van innovatieve behandelingen bespoedigd worden door deze samenwerking.

Daarenboven, geeft de inbedding binnen een grotere vakgroep een krachtere positie binnen de organisatie.

Inmiddels is ook een platform "Chirurgische zorg bij kinderen" geïnitieerd. Deze bestaat uit alle specialisten die bij de chirurgische behandeling van kinderen betrokken zijn, zoals de kinderchirurgen, kinderneurochirurgen, kinderurologen, kinderorthopeden, cardiothoracale chirurgie, KNOartsen en kinderanesthesisten. Zij hebben een adviserende rol bij alle zaken die de chirurgische zorg van kinderen aangaan, zoals de opzet van de nieuwe kinderoperatiezalen en het nieuwe beddenhuis.

In de loop van 2020 worden de nieuwe kinderoperatiezalen in gebruik genomen. Deze operatiezalen zijn van alle denkbare moderne faciliteiten voorzien op het gebied van ICT en communicatie, beeldvorming en navigatie, endosuites voorbereid voor hybride procedures en de chirurgische robot. 
In Maastricht zullen dagelijks twee kinderzalen operationeel zijn voor alle procedures bij kinderen. Parellel aan onze ontwikkeling, zien we dat ook bij de andere vakgroepen. Dit is van groot belang aangezien de behandeling van het overgrote deel van de kinderen multidisciplinair van aard is. Onze verdere ontwikkeling is alleen mogelijk als de andere vakgroepen zoals de kindergeneeskunde en de kinderanesthesie, met ons mee ontwikkelen. Op dit moment hebben we alleen al in Maastricht 4 kinder-gastroenterologen en 3 kinderlongartsen. We hebben tevens een fantastische capabele groep kinderanesthesiologen die uitstekend werk leveren. Ook deze groepen staan open voor verdere samenwerking lokaal en over de grenzen.

Op het klinische gebied zijn onze speerpunten onder te brengen bij de kinder-gastrointestinale chirurgie, de kinder-lever/pancreas chirurgie en kinderthoraxchirurgie. Daarenboven is de minimaal invasieve chirurgie en de verdere ontwikkeling daarvan binnen de kinderchirurgie een belangrijk speerpunt.

De anorectale malformaties en de ziekte van Hirschsprung vallen onder de kinder-gastrointestinale chirurgie. In het kort is de anorectale malformatie een aandoening waarbij de anus niet of niet goed is aangelegd en de ziekte van Hirschsprung een aandoening waarbij de zenuwcellen in het onderste deel van de darm afwezig zijn, waardoor obstructie 
wordt veroorzaakt. Beide aandoeningen kunnen operatief hersteld worden. Maar zoals u zich kunt voorstellen houden veel van deze kinderen functionele problemen zoals incontinentie of ernstige obstipatie. Daar bovenop is er vaak sprake van andere begeleidende aandoeningen en problemen op het gebied van de urologie, gynaecologie, seksuologie, neurologie, enzovoorts. Kortom, er is een toegewijd team van specialisten en ondersteuners nodig om deze kinderen goed te behandelen.

Maastricht heeft een lange historie met betrekking tot de behandeling van deze aandoeningen. Daarnaast heeft zij een internationale leidende positie in de behandeling van de latere functionele darmproblemen die kunnen optreden. Alle therapiemodaliteiten kunnen hier aangeboden worden inclusief "high-end" behandelingen zoals de sacrale neuromodulatie. Momenteel zijn wij bezig met de ontwikkeling van levenslange zorgpaden, waarbij de behandeling en begeleiding van een patiënt met een anorectale malformatie gedurende het hele leven wordt vastgelegd. Uiteraard is dit een individueel en dynamisch document.

Daarbij wordt "value based medicine" en PROM's geïntroduceerd. PROM staat voor Patient Reported Outcome Measure. Dit is een belangrijk onderdeel omdat het uiteindelijk gaat om de tevredenheid en kwaliteit van leven van de patiënt. De betrokkenheid 
en invalshoek van de patiënt is anders dan die van de specialist en een goed resultaat wordt door de patiënt vaak anders gedefinieerd. En aangezien zij de ware ervaringsdeskundigen zijn, is het essentieel dat naar hen wordt geluisterd.

$\mathrm{Bij}$ het opzetten van de levenslange zorgpaden zijn in dit geval de patiëntenverenigingen voor anusatresie en Hirschsprung uit Nederland en Duitsland actief betrokken bij de opzet en uitvoering hiervan. Wij streven tevens naar een actieve participatie van patiënten en ouders in dit zorgpad.

De andere speerpunten worden op dezelfde wijze georganiseerd.

Wat betreft de volwassen leverchirurgie inclusief de transplantaties is de combinatie Aken-Maastricht het grootste centrum in Nederland. Het is een logisch gevolg dat de kinderchirurgie en de kindermaagdarmleverartsen hierbij aansluiten. De chirurgische behandeling van deze kinderen zal geconcentreerd worden in Aken.

Zo wordt de behandeling van een paar specifieke aandoeningen die een complexe infrastructuur en faciliteiten behoeven op locatie gecentreerd. De kinderoncologie uit Maastricht wordt in principe doorgestuurd naar het Princes Maxima Centrum in Utrecht op enkele uitzonderingen na, evenwel is de kinderoncologie, een speerpunt in Aken en Luik. 
Al met al heeft de Euregio Maas-Rijn een uitgebreid palet aan kinderchirurgische zorg te bieden.

In principe streven we ernaar om onze patiënten zoveel mogelijk op eigen locatie te behandelen door het chirurgisch team met de juiste expertise. Dit heeft voordelen voor de patiënt, maar ook voor de financiering van de zorg.

Alhoewel ik benoemd ben tot hoogleraar kinderchirurgie op de Strategische Leerstoel Topreferente en Topklinische zorg, waarbij de nadruk ligt op de kliniek en de patiëntenzorg, blijven ook de andere academische pijlers van groot belang. Binnen een academisch klinisch centrum zijn onderzoek en innovatie die de klinische speerpunten ondersteunen essentieel. En ook hier biedt ons netwerk interessante mogelijkheden.

Inmiddels hebben we een flinke aanloop van studenten die hun wetenschapsstage bij de kinderchirurgie invullen. Dit betreft meestal klinische audits.

Er gaan nu enkele gerandomiseerde studies van start onder andere omtrent de minimaal invasieve behandeling van liesbreuken. Dit gebeurt in samenwerking met de onderzoeksgroep van Amsterdam.

Translationeel onderzoek is de schakel tussen fundamenteel onderzoek in het laboratorium en klinisch onderzoek met het doel om praktische 
oplossingen te vinden voor recente ontwikkelingen uit het fundamentele onderzoek.

Dit soort onderzoek zorgt voor de overdracht en snelle vertaling van kennis en vernieuwende technologie naar diagnosen en behandelingen in het voordeel van de patiënt.

Deze onderzoeksprojecten zijn ingebed in het onderzoeksinstituut NUTRIM, School of Nutrition and Translational Research in Metabolism. Momenteel zijn er twee PhD-studenten, Cathelijne Heymans en Ilse de Lange, werkzaam aan deze projecten.

$E r$ is een nauwe samenwerking tussen het chirurgisch laboratorium onder leiding van prof. Steven Olde Damink en het laboratorium kindergeneeskunde onder leiding van Tim Wolfs.

Daarnaast is er een steeds nauwere samenwerking met de onderzoeksgroep van Amsterdam.

Momenteel zijn wij bezig om een research netwerk tezamen met de Uniklinik RWTH Aachen op te zetten en de samenwerking met Luik op onderzoeksgebied vorm te geven, analoog aan de opzet van de kliniek. Het huidige translationeel onderzoek wordt binnen de onderzoekslijn "Liver and Digestive Health" verricht. Het onderzoek richt zich op de maturatie van het immuunsysteem en het enterale zenuwstelsel en hun rol bij inflammatoire aandoeningen zoals de necrotiserende enterocolitis. Necrotiserende enterocolitis is een ernstige darmontsteking bij te 
vroeggeboren kinderen, die wordt gekenmerkt door het afsterven van darmen en bij de allerkleinste een belangrijke doodsoorzaak is.

Eén van de beschermende factoren bij dit ziektebeeld is moedermelk. In een speciaal organoïden-model worden verschillende componenten van de moedermelk getest om te achterhalen welke substanties of combinatie van substanties betrokken zijn bij de preventie van necrotiserende enterocolitis en we trachten het onderliggende mechanisme verder te ontrafelen.

Organoïden zijn een soort mini-orgaantjes die gekweekt worden uit cellen. We gebruiken organoïden van dierlijke en humane oorsprong. Wij vermoeden dat de resultaten van deze studies ook gebruikt kunnen worden voor andere inflammatoire aandoeningen op latere leeftijd zoals de ziekte van Crohn of colitis ulcerosa.

$E r$ is een begin gemaakt met het onderzoek naar de maturatie en rol van de enterohepatische kringloop bij aandoeningen als necrotiserende enterocolitis en afwijkingen aan de galwegen zoals de galgangatresie en de choledochuscyste.

Tevens worden momenteel studies opgezet naar de toepassing van biohybride implantaten, die deels uit biologische en deels uit synthetische materialen bestaan, in combinatie met stamcellen en andere bioactieve stoffen. 
Onderzoek naar innovatieve behandelingen bij kinderen is uitermate lastig, als gevolg van zeer restrictieve wet- en regelgeving omtrent het onderzoek bij kinderen. Deze regels zijn bedoeld om het kind te beschermen. Doch anderzijds moet dit soort onderzoek wel mogelijk blijven, omdat het kind ook recht heeft op onderzoek en nieuwe behandelingsmogelijkheden.

Dit blijft een belangrijke ethische discussie. Op dit moment is het merendeel van alle medicaties, anesthetica, chirurgische apparaten en implantaten off-label. Dit wil zeggen, dat het geneesmiddel, apparaat of implantaat niet is geregistreerd voor een indicatie, toepassing of leeftijdsgroep. Om deze reden zien we het jammer genoeg te vaak gebeuren dat de introductie van nieuwe behandelingsopties bij kinderen vele jaren vertraging oploopt ten opzichte van de volwassenen.

Technische innovaties die we in de aankomende jaren verder willen ontwikkelen zijn vooral gericht op minimaal invasieve behandelmethoden zoals endoscopische technieken, uitbreiden neuromodulatie voor een breder indicatiegebied, laparoscopische en thoracoscopische techniek en robot-geassisteerde chirurgie. Al deze onderwerpen sluiten aan bij de volwassen gebieden waar reeds een ruime ervaring in ons ziekenhuis aanwezig is. 
Om een grensoverschrijdend instituut voor de chirurgische zorg van het kind op te zetten is een uitgebreid netwerk nodig, strakke bedrijfsmatige organisatie en een aangepaste regelgeving voor de grensregio.

Op de eerste plaats is ons medisch netwerk van belang. Er moet sprake zijn van een hecht chirurgisch team die onze missie draagt. In dit kader zijn onze nestors Gerd Steinau in Aken en Toan Khuc in Luik van wezenlijk belang. Hun verworven kennis en invloed wordt ten behoeve van onze zaak ingezet.

Om één internationaal team te zijn, moeten de chirurgen in verschillende landen worden gecertificeerd en geregistreerd.

Wij streven naar de realisatie van een "academische regio" voor de kinderchirurgie. Dit betekent een goede samenwerking tussen de centrale partners MaastrichtAken-Luik en de andere ziekenhuizen in de Euregio op klinisch en academisch gebied. De kern van deze academische regio zijn het Maastricht Universitair Medisch Centrum, de Uniklinik Aachen en het Centre Hospitalier Crétien, later de Clinique du Montlegia. In deze context wil ik ook graag ons gezamenlijke hoofd van de vakgroep chirurgie, prof. Ulf Neumann, noemen, voor zijn aanhoudende steun.

Zonder deze ondersteuning zou ons project tot mislukken gedoemd zijn. 
Wij werken samen met ITEM om problemen rondom nationale en Europese wet- en regelgeving te identificeren en op te lossen. ITEM staat voor "Institute for Transnational and Euregional cross border cooperation and Motility". Deze samenwerking wordt gedragen door prof. Hildegard Schneider; hoogleraar Europees recht en bestuurder van ITEM. Binnenkort is het eerste project omtrent grensoverschrijdende professionele kwalificaties afgerond. Dit is een onderdeel van het PhD project van Lavinia Kortese. Samen met ITEM zijn er nog vele andere vragen en problemen op te lossen zoals grensoverschrijdende samenwerkingsverbanden, internationale dataregistratie en extractie, financiering van de gezondheidszorg en de privacywetgeving.

Ondersteuning van onze stakeholders is van essentieel belang en die zijn talrijk: collega's, Raden van Bestuur en ziekenhuisdirecties, universiteiten, patiëntenverenigingen, beroepsverenigingen, lokale en regionale politieke gremia zoals de provincie en het Zweckverband, nationale en Euregionale overheden. Op alle niveaus is er overleg.

Overleg omtrent de opzet en implementatie van een Euregionaal kinderchirurgisch centrum en het regelkader dat nodig is om dit te realiseren. 
Het doel is om te komen tot een internationaal instituut voor de chirurgische zorg van het kind, waardoor de zorg voor het kind in deze regio op een hoog niveau wordt gegarandeerd. Indien succesvol, kan de opzet als een blauwdruk fungeren voor andere vakgroepen, ziekenhuizen en grensregio's.

Op nationaal niveau zie ik niet het Maastricht UMC+, maar ons Euregionaal centrum als de gesprekspartner van de andere vijf kinderchirurgische centra. Naar mijn mening is de toevoeging van een groter Euregionaal centrum aan Nederland een meerwaarde. Op deze wijze kunnen wij meer bijdragen op het gebied van klinische expertise, opleiding, research en innovatie.

Vanaf het begin heb ik, op een enkele uitzondering na, uitsluitend medewerking en ondersteuning ondervonden van alle stakeholders. En dat zijn er nogal wat: collega's, vakgroepen, RVE's, raden van bestuur en ziekenhuisdirecties, universiteiten en faculteiten, ITEM, beroepsverenigingen en patiëntenverenigingen, lokale en centrale overheden, en Euregionale autoriteiten.

Het is niet mogelijk iedereen te noemen in mijn dankwoord. Daarom spreek ik bij deze mijn oprechte dank uit voor iedereen die ons ondersteund heeft, en daarbij het vertrouwen dat zij dit blijven doen. Ik zal slechts enkele separaat en kort noemen. 
Ik heb gezegd. 